\title{
HOMESCHOOLING NO BRASIL: O NOVO JUDICIÁRIO E A TRADIÇÃO
}

\section{${ }^{1}$ Rubens Beçak}

\section{RESUMO}

O homeschooling, método de ensino alternativo tem ganhado um grande número de adeptos no país, o que tem provocado um maior crescimento de demandas judiciais que questionam a validade do ensino domiciliar. O Supremo Tribunal Federal reconheceu a existência de repercussão geral no Recurso Extraordinário no 888.815-RS, que trata, justamente, da possibilidade de famílias adotarem ou não o homeschooling. Assim, o presente artigo busca a melhor compreensão do instituto, o porquê do seu amplo crescimento no país e, ainda, analisar o tratamento normativo e da jurisprudência mais recente no Brasil.

Palavras-chave: Ensino domiciliar, Ativismo judicial, Direitos fundamentais

\section{HOMESCHOOLING EN BRASIL: EL NUEVO PODER JUDICIAL Y LA TRADICIÓN}

\section{RESUMEN}

La educación en el hogar mucho más se practica en los países desarrollados se ha ganado una gran cantidad de aficionados en el país, lo que ha provocado un mayor desarrollo de las demandas cuestionando su valide. La Corte Suprema reconoció recientemente la existencia de un repunte general que es precisamente la capacidad de las familias para adoptar o no la educación en el hogar .Este artículo intenta una mejor comprensión del instituto, la razón de su gran crecimiento y también analizar el tratamiento jurídico y la jurisprudencia más reciente de la educación en el hogar en Brasil.

Palabras-claves: Educación en el hogar, Activismo judicial, Derechos fundamentales

\footnotetext{
1 Doutor em Direito pela Universidade de São Paulo - USP, São Paulo (Brasil). Professor Doutor da Universidade de São Paulo - USP, São Paulo (Brasil). E-mail: rubens.becak@gmail.com
} 


\section{INTRODUÇÃO}

O ensino domiciliar no Brasil, muito embora há muito praticado por um sem-número de famílias, não tem previsão legal no ordenamento jurídico pátrio. Dessa ausência legislativa, decorrem duas intepretações possíveis, cada uma delas árdua e coerentemente combatida por seus defensores: a que toma como devida a necessária matrícula, em escolas externas, das crianças e adolescentes - com amparo na Lei de Diretrizes e Bases da Educação ${ }^{1}$ - e, ainda, aquela em que possível a educação domiciliar, levando-se em consideração uma interpretação extensiva da própria Constituição Federal ${ }^{2}$.

Fato é que, até o presente momento, não houve regulamentação alguma da matéria no país, ao menos não por parte do Poder Legislativo. Há, atualmente, um Projeto de Lei ${ }^{3}$ sobre o tema, que aguarda parecer da Comissão de Educação da Câmara dos Deputados, sem qualquer previsão temporal de ser submetido ao plenário, todavia.

A temática ganhou especial destaque a partir do ano de 2010, quando o Ministério da Educação reconheceu a utilização de desempenho no ENEM (Exame Nacional do Ensino Médio) como certificação de conclusão desta etapa de educação. Assim, em uma interpretação extensiva, supostamente todos os aprovados no exame - ainda que adeptos do homeschooling - podem ter certificada a conclusão do ensino médio, sendo, por conseguinte, aptos a darem continuidade nos estudos em nível superior.

Estima-se que, após o reconhecimento de aludida possibilidade pelo MEC, o número de adeptos do ensino domiciliar tenha dobrado no país, sendo que, atualmente, são mais de 2.000 (duas mil) famílias que se utilizam da técnica do homeschooling com crianças e adolescentes de seu núcleo íntimo.

Como é recorrente no país, ante a inércia do Poder Legislativo, incumbe ao Poder Judiciário - e, em especial, às cortes superiores - deliberar sobre questões de interesse coletivo, sobretudo aquelas em que há substancial influência da religião na matéria a ser debatida. Não poderia ser diferente, afinal, como é cediço, o Brasil é o país com mais católicos no mundo, se considerados em números absolutos.

1 A Lei $n^{\circ}$ 9.394/96 estabelece, em seu art. $6^{\circ}$ que "é dever dos pais ou responsáveis efetuar a matrícula das crianças na educação básica a partir dos 4 (quatro) anos de idade".

2 será promovida e incentivada com a colaboração da sociedadé, visando ao pleno desenvolvimento da pessoa, seu preparo para o exercício da cidadania e sua qualificação para o trabalho" (grifou-se o trecho utilizado como fundamento pelos adeptos do homeschooling no Brasil).

${ }^{3}$ Projeto de Lei $n^{\circ}$ 3179/2012, de autoria do Deputado Federal Lincoln Portela, que busca acrescentar o parágrafo ao art. 23, da própria Lei $\mathrm{n}^{\circ}$ 9.394/96, para dispor sobre a possibilidade de oferta domiciliar de educação básica. 
Neste diapasão, recentemente têm as principais cortes do país se manifestado sobre a temática, em geral favoravelmente à possibilidade da educação domiciliar; a questão será em breve decidida pelo Supremo Tribunal Federal, em processo de relatoria do Ministro Luís Roberto Barroso que, quando do reconhecimento da repercussão geral, destacou ser o tema de interesse coletivo, definindo que "a controvérsia envolve a definição dos contornos da relação entre o Estado e a família na educação das crianças e adolescentes, bem como os limites da autonomia privada contra imposições estatais".

É justamente este o escopo do presente artigo: verificar, à luz dos mais recentes entendimentos jurisprudenciais, a evolução do ensino domiciliar no Brasil - levando-se em consideração o fato de se tratar de país de grande influência religiosa na tomada das mais importantes decisões políticas -, questionando-se, ainda, se há uma mudança de paradigma sobre o tema nas principais cortes do Poder Judiciário.

\section{OBJETIVOS}

O presente artigo tem como principal objetivo a análise do instituto do homeschooling no Brasil, buscando entender as causas e consequências, para o ensino no país, de referido método de educação.

Para tanto, necessário será esmiuçar o instituto, destacando, em especial, a sua aceitabilidade nas mais diferentes áreas do mundo, sobretudo em países considerados desenvolvidos.

Buscar-se-á, ainda, a compreensão do porquê, no Brasil, tantas famílias passarem a adotar o homeschooling como método de ensino a crianças e adolescentes e, ainda, verificar possível semelhança - ou total dissonância - com as causas para a adoção do instituto em outros países do mundo.

Enfim, tratar-se-á do aspecto normativo do instituto, destacando os projetos de leis que buscaram a sua regulamentação e, ainda, de como o Judiciário brasileiro tem se manifestado acerca da possibilidade de adoção do homeschooling no país.

\section{METODOLOGIA}

A pesquisa, no que tange ao material, terá como base doutrina nacional e estrangeira; dada a incipiência do estudo do instituto do homeschooling no Brasil, serão usadas, de igual modo, notícias jornalísticas que retratam famílias que adotam o método de educação com seus filhos e adolescente. 
Outra importante fonte material a ser analisada serão os julgados proferidos pelos Tribunais que versam sobre a matéria, dando-se especial destaque à recente decisão do Supremo Tribunal Federal, que reconheceu a repercussão geral na temática posta.

Com relação aos métodos, serão utilizados: a) o método de direito comparado histórico, com preocupação em formular a linha histórica de desenvolvimento da matéria, assim como confrontar as formulações recentes (legislações, doutrinas, jurisprudência etc.) de ordenamentos jurídicos estrangeiros com o do Brasil; e b) o método empírico, à medida que a busca por julgados, e a análise das mesmas, fará parte essencial do conteúdo da pesquisa que se pretende realizar.

\section{O HOMESCHOOLING COMO MÉTODO DE EDUCAÇÃO}

O ensino domiciliar, como método de educação substitutivo ao tradicional ministrado em estabelecimentos oficiais, tem como principal fundamento a insatisfação, dos próprios alunos e de seu núcleo familiar próximo, com as técnicas comumente adotadas, seja por razões ideológicas, seja, ainda, pelos baixos índices de qualidade do ensino ${ }^{4}$ (LYMAN, p. 2).

Pois bem, antes de se adentrar na realidade educacional brasileira, contudo, imperiosa se mostra a demonstração da técnica do homeschooling, fundada, essencialmente, no processo de ensino-aprendizagem dos pais do educando.

O ensino domiciliar não é considerado, per se, um método de aprendizagem; é, mais que isso, verdadeira modalidade de educação, que possui características específicas que a distinguem de outras, como a escolar e à distância, comumente verificadas na realidade brasileira, com especial destaque ao respeito das limitações individuais de cada um dos alunos, tratados, no método tradicional de ensino, como se iguais fossem (LACANALLO, et alli, p. 3).

Como destacado supra, os principais direcionadores e responsáveis pelo processo de ensino e aprendizagem no ensino domiciliar são os pais dos alunos, de tal forma que a educação ocorre no seio da própria família; isso não significa, contudo, que as técnicas adotadas em tal modalidade restringem-se ao contexto doméstico, sendo plenamente possível, ainda que inseridos em homeschooling, que os adeptos de tal método estejam plenamente imersos em ambientes externos, acompanhados, contudo, dos pais ou responsáveis (AGUIAR, p. 3).

\footnotetext{
${ }^{4}$ O Brasil, por exemplo, foi o último colocado no PISA (Programa Internacional de Avaliação de Alunos), teste esse que mediu o desempenho de estudantes com 15 anos nas redes pública e privada de ensino, de 32 países.
} 
Historicamente destinada às elites intelectuais da sociedade - imagem essa que, nos últimos anos, tem sido modificada, com a adoção da metodologia por famílias das mais diferentes classes sociais -, o homeschooling, para que produza os efeitos esperados, utiliza-se de uma série de técnicas, das mais diversas possíveis. Eis, inclusive, uma das principais características do ensino domiciliar: a total flexibilidade dos conteúdos ministrados, da carga horária destinada, dos dias letivos e, enfim, do calendário adotado pelos agentes envolvidos (ANDERSON, p. 2).

Muito embora haja, de fato, a mencionada flexibilidade no ensino domiciliar, fato é que seus adeptos costumam se utilizar de algumas técnicas bem definidas - ou, ao menos, de parte delas -, com especial ênfase àquelas, de igual modo, adotadas por muitas escolas públicas e privadas, como o método Montessori, o concebido por Charlotte Mason, a pedagogia Waldorf e outros tantos ligados à ideia construtivista de educar (LYMAN, p. 6).

Em outras palavras; não se pode afirmar que a técnica do homeschooling é recente nem tampouco inovadora. Há séculos - talvez milênios - praticada pelas mais diferentes sociedades - desde quando não havia escolas tradicionais, de frequência obrigatória -, os adeptos do ensino domiciliar não buscam, necessariamente, métodos jamais vistos nos estabelecimentos oficiais de ensino (LYMAN, p. 4). O que se pretende com o homeschooling, é uma educação voltada às particularidades dos alunos - atenção essa que só pode ser melhor entendida e aplicada pelo núcleo familiar mais próximo - de tal sorte que os educandos, considerados em sua individualidade, sejam contemplados com uma formação mais humanista, subjetiva e, enfim, mais completa para as diferentes situações da vida.

\subsection{O homeschooling no mundo}

O homeschooling, como método de educação, tem ampla aceitação em diversos países do mundo, sendo majoritariamente adotado nos Estados Unidos da América, no Reino Unido, na Índia, na África do Sul, na Austrália e na Nova Zelândia, muito embora legalizado em muitos outros Estados, com especial destaque ao México e à Indonésia 5 .

Na Nova Zelândia, estima-se que $1 \%$ de todos os estudantes em idade escolar - mais de 6 mil alunos - são educados pelo sistema de ensino domiciliar. É importante destacar, especialmente, que, desde 1998, houve um aumento de 23,6\% no número de pessoas registradas sob essa modalidade de educação.

\footnotetext{
5 As informações aqui tratadas foram obtidas junto da página da HSLDA - Home School Legal Defense Association, disponível em: https://www.hslda.org/hs/international/. Acesso em 15 de Dezembro de 2015.
} 
No país vizinho, Austrália, o ensino domiciliar é legalizado em todos os estados e territórios do país; são cerca de 30.000 as famílias que adotam formas alternativas de educação de seus filhos, a maioria delas adepta do homeschooling.

$\mathrm{Na}$ África do Sul, o ensino domiciliar era considerado ilegal até 1996; atualmente, conta com um considerável número de adeptos que, segundo estimativas não oficiais, cresce na proporção de $20 \%$ ao ano. Estimam-se que sejam cerca de 75.000 os estudantes que, atualmente, são educados pelo sistema de ensino domiciliar.

Na Inglaterra e no País de Gales, o ensino domiciliar é considerado legal desde 1944, ano em que editado o 'Education Act'; o que se destaca em tais países é a total desnecessidade de se informar, às autoridades competentes, a educação domiciliar de determinada pessoa, a não ser que esta tenha, anteriormente, sido matriculada em instituição oficial ${ }^{6}$.

Por estarem em países em que o homeschooling está regulamentado há mais tempo e, ainda, dada a desnecessidade de registro de ensino domiciliar - acredita-se que sejam cerca de 100.000 os alunos educados por este método de educação, sem se considerar Escócia ${ }^{7}$ e Irlanda.

É, contudo, nos Estados Unidos da América que o homeschooling conta com o maior número de adeptos e, por conseguinte, com a melhor regulamentação e o mais aprofundado estudo da temática.

Adotado por cerca de 2 milhões de estudantes - ou 3,4\% da população em idade escolar -, o homeschooling era majoritariamente aplicado, nos Estados Unidos, em áreas rurais até 1970 - até por um questão de cunho logístico -, quando o estudo mais profícuo acerca do tema - com a produção acadêmica de várias obras - tornou tal metodologia mais acessível à população urbana (LYMAN, p. 5) (ANDERSON, p. 3)..

A temática está regulamentada nos 50 Estados do país; em âmbito judicial, muito embora não tenha a Supreme Court se manifestado diretamente sobre o ensino domiciliar, no caso Wisconsin v. Yoder, de 1972, foi reconhecido o direito da família em manter as crianças fora do ambiente escolar, por motivos religiosos.

Dada a proporção do homeschooling nos Estados Unidos, várias são as organizações existentes com objeto exclusivo na temática, das quais se destacam, especialmente, a HSLDA - Home School Legal Defense Association - e a The Home School Foundation.

\footnotetext{
${ }^{6}$ Há, inclusive, uma página do governo na rede mundial de computadores com tais informações. Disponível em: https://www.gov.uk/home-education

${ }^{7} \mathrm{Na}$ Escócia, o homeschooling foi regulamentado em 1980, com a edição do 'Scottish Education Axt' e em 2001, com o Standards in Scotland's Schools Act'; na Irlanda, por seu turno, o reconhecimento do ensino domiciliar deu-se na própria constituição do país, no art. 42.
} 
De se destacar, enfim, que várias são as personalidades americanas que foram educadas com fundamento no homeschooling, como, por exemplo, os ex-presidentes Theodore Roosevelt, Woodrom Wilson e Franklin Roosevelt, os inventores Thomas Edison e Alexander Graham Bell e outras tantas celebridades da música e dos esportes americanos.

\subsection{O homeschooling no Brasil}

No Brasil, o ensino domiciliar fundamenta-se, essencialmente, na crise da educação oficial das instituições do país. As questões predominantemente religiosas - que amparam os pais e responsáveis pelos educandos em muitos dos estados em que adotado o homeschooling, com especial destaque aos Estados Unidos - não são tidas como causa predominante para a adoção desta metodologia no Brasil.

Segundo a ANED - Associação Nacional de Educação Domiciliar - o homeschooling vem ganhando, a despeito da falta de previsão legislativa acerca do instituto, cada vez mais adeptos ${ }^{8}$, estimando serem 2.000 (duas mil) famílias que educam seus filhos em casa no Brasil.

No país com o maior número de católicos apostólicos romanos no mundo, se considerados em números absolutos, as causas para adoção do ensino domiciliar, como destacado supra, não guardam necessária pertinência com a liberdade religiosa ${ }^{9}{ }^{10}$, direito previsto na Constituição Federal, em seu art. 5º VI. É, ao contrário, por conta da patente crise do sistema educacional brasileiro - seja pela metodologia adotada, seja, ainda, pela ineficiência dos agentes educadores, até mesmo em coibir certos abusos perpetrados no ambiente escolar $^{11}$ - e, ainda, pela necessidade de maior convívio familiar ${ }^{12}$ que optam os pais dos educandos pelo método do homeschooling.

\footnotetext{
${ }^{8}$ É relevante destacar o apoio da população brasileira à possibilidade de educação domiciliar das crianças e adolescentes. Em pesquisa virtual realizada pela Câmara dos Deputados, 77,83\% dos entrevistados concordaram com a aprovação do PL n ${ }^{\circ}$ 3179/2012 - melhor tratado infra -, num universo de 38.696 votos considerados. In: http://www2.camara.leg.br/enquetes/resultadoEnquete/enquete/3C0806AC-C6F4-4544-9C5DBC508CF3CC97;jsessionid=2EB1C22DA1788518EB279617F28176AB.node2

${ }^{9}$ Não foi localizado, no material pesquisado, nenhum entrevistado que tenha apontado a suposta ofensa à liberdade religiosa como causa determinante para a utilização do homeschooling; não se ignora, contudo, que certamente são muitas as famílias que educam seus filhos em casa por razões de cunho religioso.

${ }^{10}$ É importante destacar que, no Brasil, são muitas as instituições educacionais oficiais que, em seu currículo pedagógico, oferecem ensino religioso; possivelmente, essa seja a causa para que não se amparem os adeptos do homeschooling na violação à liberdade de consciência quando da adoção da técnica.

${ }^{11}$ Em entrevista concedida ao site da BBC, Ricardo Iene, cofundador da ANED, destaca que passou a adotar o ensino domiciliar em razão, dentre tantos outros fatores, do bullying que sofriam os seus filhos em uma escola de Belo Horizonte (MG), por conta do sotaque baiano que tinham; o pai alerta que foi "várias vezes na escola, reclamar, conversar, tentar resolver esses problemas. Mas nunca adiantou". In: www.bbc.com/portuguese/noticias/2013/11/131104_educacao_domiciliar_abre_vale_mdb

${ }^{12}$ A necessidade de estabelecimento de um maior convívio familiar é destacada, de igual modo, em outras entrevistas veiculadas pela imprensa brasileira; ao estabelecer as vantagens do homeschooling, uma mãe destaca
} 
Em maio de 2015, foi divulgado um ranking mundial de qualidade de educação, elaborado pela Organização para a Cooperação e Desenvolvimento Econômico (OCDE); na lista, o Brasil ocupa a $60^{\mathrm{a}}$ posição, entre os 76 países avaliados, o que demonstra, de modo objetivo, a qualidade da educação oficial do estado brasileiro.

Assim, insatisfeitas com o ensino praticado em instituições oficiais, muitas são as famílias que passaram a optar pelo homeschooling no Brasil (FRANCIULLI NETTO, p. 14). Os resultados até então verificados, na opinião dos envolvidos com o ensino domiciliar, são os melhores possíveis: aqueles que educados foram pela técnica pretendem se utilizar desta metodologia futuramente, quando da educação das novas gerações ${ }^{13}$.

Muito embora seja, a cada dia, maior o número de famílias que se utilizam da metodologia do homeschooling no país, não houve regulamentação, por parte do Poder Legislativo, da temática posta, de tal forma que, atualmente, há verdadeiro vazio normativo sobre o ensino domiciliar, como será melhor tratado infra.

\section{O TRATAMENTO NORMATIVO DO HOMESCHOOLING NO BRASIL}

Apesar de praticado por muitas famílias, não houve a devida regulamentação do homeschooling no Brasil, pelo Poder Legislativo, a quem compete a edição de leis sobre a temática, nos termos do art. 24, IX, da Constituição Federal.

É importante destacar, antes de se adentrar na pertinência dos divergentes argumentos levantados na discussão, que tramita na Câmara dos Deputados, - Casa Iniciadora do processo legislativo brasileiro -, o Projeto de Lei $n^{\circ} 3179 / 2012^{14}$, de autoria do Deputado Lincoln Portela, que prevê o acréscimo de parágrafo ao artigo 23, da Lei de Diretrizes e Bases da Educação ${ }^{15}$, para dispor sobre a possibilidade de oferta domiciliar de ensino.

que "a principal é a convivência familiar. Em cidades como São Paulo, pode se perder muito tempo com o deslocamento".

http://www.bbc.com/portuguese/noticias/2013/11/131104_educacao_domiciliar_familia_vale_mdb

${ }^{13}$ Neste sentido, são os depoimentos dados em algumas entrevistas jornalísticas, cujo conteúdo foi transcrito para a internet. Davi, educado pela técnica do homeschooling, em entrevista concedida ao jornal "A Folha de São Paulo" criticou o ensino formal e afirmou que "vou querer educar meus filhos com ensino domiciliar". In: http://www1.folha.uol.com.br/equilibrioesaude/2015/02/1594329-ex-alunos-contam-experiencia-de-ensinodomiciliar-que-cresce-no-pais.shtml

${ }^{14}$ Antes desse, outros projetos de lei sobre a mesma temática foram sumariamente rejeitados pela Comissão de Educação - no 6.001, de 2001; n 6.484, de 2002; n 3.518, de 2008; e n 4.122, de 2008. Os argumentos utilizados pela Comissão foram tomados à luz da Constituição Federal, do Código Penal, do Estatuto da Criança e do Adolescente e da Lei de Diretrizes e Bases da Educação.

${ }^{15}$ Caso aprovado o projeto de lei conforme proposto pelo Deputado, assim ficaria o dispositivo normativo alterado: "Art. 23․ A educação básica poderá organizar-se em séries anuais, períodos semestrais, ciclos, alternância regular de períodos de estudos, grupos não-seriados, com base na idade, na competência e em outros critérios, ou por forma diversa de organização, sempre que o interesse do processo de aprendizagem assim o recomendar. (...)§ $3^{\circ}$ É facultado aos sistemas de ensino admitir a educação básica domiciliar, sob a responsabilidade dos pais ou tutores responsáveis pelos estudantes, observadas a articulação, supervisão e 
Importante destacar que, recentemente, a proposição do Deputado Lincoln Portela recebeu parecer favorável da Comissão de Educação ${ }^{16}$, que sugeriu algumas modifícações ${ }^{17}$ ao texto inicialmente levado à Câmara. Atualmente, o Projeto de Lei encontra-se no aguardo de apreciação pela Comissão de Constituição e Justiça, do Congresso Nacional, que analisará a constitucionalidade da proposta normativa apresentada.

Assim, dada a ausência de expressa previsão normativa do tema em questão, tanto aqueles que são críticos ao instituto como seus mais assíduos adeptos utilizam-se de técnicas interpretativas para defender a sua proibição, no caso daqueles, ou, ainda, a sua plena possibilidade, para os praticantes da metodologia.

Passa-se, por ora, a explicitar os argumentos trazidos por cada um dos defensores desta discussão.

Aqueles que defendem a impossibilidade do ensino domiciliar no ordenamento jurídico brasileiro, fundamentam-se na literalidade de alguns dispositivos legais, como, por exemplo, o art. $6^{\circ}$, da Lei de Diretrizes e Bases da Educação ${ }^{18}$ e, ainda, o art. 129, V, do Estatuto da Criança e do Adolescente ${ }^{19}$.

Como penalização àqueles que deixam de efetuar a matrícula de seus filhos em estabelecimentos oficiais, os que pugnam pela impossibilidade de adoção do homeschooling

avaliação periódica da aprendizagem pelos órgãos próprios desses sistemas, nos termos das diretrizes gerais estabelecidas pela União e das respectivas normas locais".

${ }^{16}$ Em seu parecer, a Deputada Professora Dorinha Seabra Rezende destacou a pertinência do Projeto de Lei: "Um dos méritos da proposição, portanto, é o de admitir, sem obrigar, a possibilidade de uma diferenciação na responsabilidade pela educação básica, autorizando os sistemas de ensino a prever, em suas normas, a alternativa de que pais e tutores se responsabilizem diretamente pela condução do processo ensino/aprendizagem de crianças e jovens de suas famílias. Ressalte-se novamente que o projeto especifica que deve haver diretrizes que assegurem a articulação, a supervisão e a avaliação periódica da aprendizagem pelos órgãos próprios dos sistemas de ensino".

${ }^{17}$ Eis o substitutivo ao Projeto de Lei n 3.179/2012: “Art. 23 - A educação básica poderá organizar-se em séries

anuais, períodos semestrais, ciclos, alternância regular de períodos de estudos, grupos não-seriados, com base na idade, na competência e em outros critérios, ou por forma diversa de organização, sempre que o interesse do processo de aprendizagem assim o recomendar. (...)§ $3^{\circ}$ Os sistemas de ensino admitirão a educação básica domiciliar, sob a responsabilidade dos pais ou tutores responsáveis pelos estudantes, observadas a articulação, supervisão e avaliação periódica da aprendizagem pelos órgãos próprios desses sistemas, nos termos das diretrizes gerais estabelecidas pela União e das respectivas normas locais, que contemplarão especialmente: I autorização pelo órgão competente do sistema de ensino; II - a avaliação prévia, pelo órgão competente do sistema de ensino, da qualificação dos pais ou responsáveis para conduzir o processo de ensino e aprendizagem do estudante; III - obrigatoriedade de matrícula do estudante em escola pública ou privada em regular funcionamento; IV - manutenção de registro oficial das famílias optantes pela educação domiciliar; V cumprimento de currículo mínimo e avaliação da aprendizagem, nos termos e na periodicidade estabelecidos no projeto pedagógico da escola em que o estudante estiver matriculado; VI - participação do estudante nos exames do sistema nacional e local de avaliação da educação básica; VII - previsão de inspeção educacional, pelo órgão competente do sistema de ensino. no ambiente em que o estudante estiver recebendo a educacão domiciliar".

${ }^{18}$ Art. $6^{\circ}$ - É dever dos pais ou responsáveis efetuar a matrícula das crianças na educação básica a partir dos 4 (quatro) anos de idade.

${ }^{19}$ Art. 129 - São medidas aplicáveis aos pais ou responsável: (...) V - obrigação de matricular o filho ou pupilo e acompanhar sua frequência e aproveitamento escolar. 
no Brasil entendem ser cabível a sanção prevista no art. 246, do Código Penal ${ }^{20}$ - crime de $^{2}$ abandono intelectual -, para além das penalidades administrativas previstas no próprio Estatuto da Criança e do Adolescente ${ }^{21}$.

Verifica-se, portanto, que os defensores da impossibilidade da adoção da técnica ora estudada sustentam-se, em âmbito normativo, na redação de dispositivos legais vigentes no ordenamento jurídico pátrio.

A missão dos propagadores do homeschooling no país, contudo, é mais árdua, dada a inexistência de previsão legal - em vigência, ao menos, dado o atual trâmite do Projeto de Lei no 3179/2012, destacado supra - do instituto no ordenamento jurídico pátrio: amparam-se, seus defensores, em técnicas interpretativas, à luz de princípios constitucionais, para justificar a possibilidade de se utilizarem o homeschooling na educação de seus filhos (AGUIAR, p. 1).

Estabelece a Constituição Federal, em seu art. 205, que "a educação, direito de todos e dever do Estado e da família, será promovida e incentivada com a colaboração da sociedade, visando ao pleno desenvolvimento da pessoa, seu preparo para o exercício da cidadania e sua qualificação para o trabalho". Em sentido símile, a própria Lei de Diretrizes e Bases da Educação, estatui, no art. $2^{\circ}$, que "a educação, dever da família e do Estado, inspirada nos princípios da liberdade e nos ideais de solidariedade humana, tem por finalidade o pleno desenvolvimento do educando, seu preparo para o exercício da cidadania e sua qualificação para o trabalho" (FRANCIULLI NETTO, p. 8).

Tanto no dispositivo constitucional mencionado quanto no artigo da Lei $\mathrm{n}^{\circ}$ 9.394/1996 verifica-se uma inerente repartição de deveres quanto à prestação de educação, entre Estado e família, base da sociedade, nos termos do art. 226, da própria Constituição Federal.

Para fundamentar o homeschooling, ainda, possível invocar a Declaração Universal dos Direitos Humanos - da qual o Brasil é signatário - que, em seu art. XXVI, estabelece que "os pais têm prioridade na escolha do gênero de instrução que será ministrada a seus filhos" (AGUIAR, p. 3).

Assim, os que defendem a possibilidade de utilização da técnica do homeschooling amparam-se, essencialmente, no inerente dever da família em prestar educação aos seus filhos

\footnotetext{
${ }^{20}$ Art. 246 - Deixar, sem justa causa, de prover à instrução primária de filho em idade escolar: Pena - detenção, de quinze dias a um mês, ou multa.

${ }^{21}$ O próprio ECA estabelece, em seu art. 249, pena para quem descumprir os deveres inerentes ao poder familiar: “Art. 249. Descumprir, dolosa ou culposamente, os deveres inerentes ao pátrio poder poder familiar ou decorrente de tutela ou guarda, bem assim determinação da autoridade judiciária ou Conselho Tutelar: Art. 249. Descumprir, dolosa ou culposamente, os deveres inerentes ao pátrio poder poder familiar ou decorrente de tutela ou guarda, bem assim determinação da autoridade judiciária ou Conselho Tutelar”.
} 
- obrigação essa verificada tanto na Constituição Federal quanto na Lei de Diretrizes e Bases da Educação - e, ademais, na escolha dos pais da forma de instrução que será ministrada, com fundamentos nos próprios dispositivos constitucionais ${ }^{22}$ e na Declaração Universal de Direitos Humanos (FRANCIULLI NETTO, p. 7).

Ainda em âmbito infraconstitucional, a edição da Portaria Normativa $\mathrm{n}^{\circ}$ 4, de 11 de Fevereiro de 2010, do Ministério da Educação, talvez seja considerado o maior dos fundamentos dos adeptos do homeschooling; por referido ato normativo secundário, passou a ser possível a emissão de certificado de conclusão do ensino médio por meio de um critério estritamente objetivo, acessível, inclusive, às pessoas que não frequentaram instituições oficiais de ensino: o Exame Nacional do Ensino Médio (ENEM) (AGUIAR, p. 7).

Com a vigência desta Portaria, todo e qualquer interessado em obter certificação de conclusão de ensino médio - outrora acessível, apenas e tão somente, àqueles que tivessem frequentado estabelecimento oficiais de ensino - passou a ser possível a todos aqueles que atingirem determinada pontuação mínima no exame, além de outros requisitos estabelecidos pelo próprio ato normativo ${ }^{23}$.

Assim, sendo admitido, pelo ordenamento jurídico, o reconhecimento da conclusão do ensino médio - e a possibilidade de se acessar o ensino superior - por meio de uma prova objetiva, além do preenchimento dos demais requisitos estabelecidos na Portaria Normativa, possível se torna, aos adeptos do homeschooling, que alunos que jamais tenham frequentado as instituições oficiais de ensino - e educados em casa, por exemplo -, se aprovados no Exame Nacional do Ensino Médio, consigam receber o certificado de conclusão de referida etapa, depreendendo-se, em uma interpretação extensiva, a permissividade do ordenamento jurídico com a técnica do ensino domiciliar (AGUIAR, p. 19).

\footnotetext{
${ }^{22}$ Como o princípio da autonomia privada, muito embora não previsto expressamente na Constituição, há muito admitido no ordenamento - até mesmo amparado na dignidade da pessoa humana, expressa no art. $1^{\circ}$, III, da Carta Magna; destaca-se neste sentido, ainda, o princípio da legalidade, este verificado no art. $5^{\circ}$, II, da Constituição Cidadã, pelo qual ninguém é obrigado a fazer ou deixar de fazer algo senão em virtude de lei (em sentido estrito).

${ }^{23}$ Estabelece a Portaria Normativa $n^{\circ}$ 4, de 11 de Fevereiro de 2010, do Ministério da Educação: “Art. $1^{\circ}$ O interessado em obter certificação no nível de conclusão do ensino médio ou declaração de proficiência com base no Exame Nacional do Ensino Médio - ENEM deverá acessar o sítio eletrônico (http://sistemasenem2.inep.gov.br/Enem2009/), com seu número de inscrição e senha, e preencher o formulário eletrônico de solicitação de certificação, de acordo com as instruções pertinentes, até o dia 31 (trinta e um) de março de 2010.

Art. $2^{\circ} \mathrm{O}$ interessado deverá observar os seguintes requisitos:

I - ter 18 (dezoito) anos completos até a data de realização da primeira prova do ENEM;

II - ter atingido o mínimo de 400 pontos em cada uma das áreas de conhecimento do ENEM;

III - ter atingido o mínimo de 500 pontos na redação.

Parágrafo único. Para a área de linguagens, códigos e suas tecnologias, o interessado deverá obter o mínimo de 400 pontos na prova objetiva e, adicionalmente, o mínimo de 500 pontos na prova de redação".
} 
Superado, pois, o aspecto normativo do homeschooling no ordenamento jurídico brasileiro, passa-se, no próximo capítulo, à análise do tratamento do Judiciário sobre o tema, que tem se modificado substancialmente nos últimos anos, em consonância com o exponencial crescimento da adoção da técnica no país.

\section{O HOMESCHOOLING E O NOVO JUDICIÁRIO}

No Brasil, é comum que as regulamentações legislativas não acompanhem a rápida evolução da sociedade; justamente por essa razão, a despeito do homeschooling ter ganhado um grande número de adeptos, inexiste qualquer texto legal que preveja, expressamente, a possibilidade de utilização de referido método de ensino, como já destacado supra.

Ao Judiciário, contudo, como último garantidor da observância dos direitos fundamentais, não deixam de chegar as mais diferentes demandas acerca do homeschooling, consistentes, em geral, no pedido de reconhecimento de validade de tal método de ensino a fim de se possibilitar o acesso ao ensino superior aos interessados.

Não poderia ser diferente; afinal, em um país em que Legislativo e Executivo mostram-se inertes ante os mais relevantes clamores da sociedade - sobretudo por conta de interesses políticos, à espera das próximas eleições -, incumbe ao Judiciário -cuja participação popular na escolha de seus representantes é inexistente, eis que formado por magistrados de carreira, em sua maioria - a definição e implementação de políticas públicas, para posterior acompanhamento e melhor definição pelos outros Poderes constituídos (COMPARATO, p. 290).

No Brasil, a atuação exacerbada do Judiciário - em sentido positivo - tem uma especial causa; o fenômeno da constitucionalização abrangente (COMPARATO, p. 293). A Constituição Federal atualmente vigente cuida da separação de poderes, da organização do Estado e dos direitos fundamentais, como as constituições em geral, mas também trata da ordem econômica, de sistema previdenciário, de proteção do meio ambiente, da criança e do adolescente - temas relacionados ao homeschooling - do idoso, da polícia, dos cartórios, dos índios.

A judicialização - fenômeno pelo qual questões relevantes do ponto de vista político, social ou moral são decididas, em caráter final, pelo Judiciário - é um fato, potencializado no Brasil por conta da constitucionalização abrangente e, ainda, por conta da já mencionada ineficiência do Legislativo e Executivo na implementação das políticas públicas mais básicas.

Com o homeschooling, não tem sido diferente; ante a inércia dos demais Poderes constituídos em tratar, expressamente, da matéria posta, é o Judiciário quem tem proferido as 
decisões que indicam o futuro normativo do instituto. A despeito da inexistência de sua previsão no ordenamento jurídico - como já destacado nas seções anteriores -, tem sido reconhecida, pelos juízes e tribunais do país, a possibilidade de as famílias adotarem o ensino domiciliar como método de educação, em especial após a edição da Portaria Normativa $\mathrm{n}^{\circ} 4$, de 11 de Fevereiro de 2010, do Ministério da Educação, que trouxe a possibilidade de reconhecimento de conclusão do ensino médio com base no desempenho do candidato no ENEM.

Neste sentido, é, por exemplo, um dos mais paradigmáticos casos de homeschooling do Brasil, ocorrido no Estado do Paraná, no Sul do país. Moradora da cidade de Maringá, uma família decidiu tirar os filhos da escola e, atualmente, os educa em casa com o aval do Judiciário.

Com o apoio do Ministério Público local, os pais - ambos profissionais da área da educação - conseguiram convencer o Judiciário de que é possível educar os fillhos em casa; na decisão proferida, o Juiz de Direito determinou que fossem realizadas avaliações constantes dos conteúdos apreendidos em casa, provas essas que são realizadas em uma escola pública da região.

No julgado em apreço, reconheceu-se a possibilidade de adoção do homeschooling com fundamento na interpretação extensiva dos dispositivos normativos que tratam a matéria; a Promotora de Justiça do caso afirmou, à época, que o fato do ensino domiciliar não estar expressamente contemplado no sistema educacional brasileiro não restringe o acesso a esse método, dada a ausência, de igual modo, de sua vedação expressa.

Em outro recente caso, deste ano de 2015, o Tribunal Regional Federal da $1^{\text {a }}$ Região, em Brasília, concedeu liminar favorável a Lorena Dias, então com 17 anos, para que obtivesse o certificado de conclusão do ensino médio - com fundamento na nota obtida pelo ENEM - a despeito de ter estudado, de 2011 a 2014, em casa, com o auxílio de seus pais.

Neste caso, o fundamento adotado pelo Judiciário foi menos exegético; amparou-se a decisão na mencionada Portaria Normativa $n^{\circ}$ 04, do Ministério da Educação, que reconhece, expressamente, a possibilidade de emissão de atestado de conclusão do ensino médico pelo desempenho obtido pelo candidato no ENEM.

É recente, contudo, esse aparente posicionamento jurisprudencial; assim como ocorreu com diversos projetos de lei que tentaram regular a matéria no país - todos sumariamente rejeitados pelo Legislativo - vários foram os casos em que se negou a possibilidade de adoção do homeschooling por famílias interessadas.

No mais paradigmático deles - e o primeiro conhecido do Brasil -, uma família de Anápolis, no Estado de Goiás, levou à ação do Poder Judiciário sobre o tema no país, que 
recebeu parecer da Câmara de Educação Básica do Conselho Nacional de Educação, manifestação do Ministério Público Federal e, enfim, julgamento pelo Superior Tribunal de Justiça, concluído em 2002.

Dos cinco filhos da família, os três primeiros vivenciaram a experiência de estudar em casa; quando o mais velho estava prestes a completar o primeiro ciclo do ensino fundamental, os pais decidiram apresentar requerimento de validação do ensino ministrado no lar junto ao Conselho de Educação de Goiás, que remeteu, de pronto, o caso ao Conselho Nacional de Educação, alegando que o tema extrapolava o âmbito de decisões daquele órgão.

Após parecer do CNE negando o pedido da família - de relatoria de Ulysses de Oliveira Passinet, que fundamentou seu voto na Lei de Diretrizes e Bases da Educação e na Constituição Federal, justamente levando-se em consideração dispositivos mencionados no capítulo anterior -, esta impetrou mandado de segurança perante o Ministro Presidente do Superior Tribunal de Justiça, alegando terem o direito líquido e certo a educarem seus filhos em casa, à luz das normas constitucionais do Brasil.

O Ministério Público Federal, em decisão surpreendente, manifestou-se favoravelmente ao pleito dos pais. Para tanto, o subprocurador-geral da República, Antônio Augusto César, fundamentou-se na Declaração Universal dos Direitos Humanos e na Constituição Federal de 1988.

Apesar da manifestação favorável do MPF, o Superior Tribunal de Justiça - em posicionamento defendido por cinco Ministros -, em processo relatado pelo Ministro Francisco Peçanha Martins, denegou a ordem pleiteada, sob o fundamento de não haver declaração expressa que regulamentasse o homeschooling no país, "não se podendo pretender o preenchimento de tal lacuna pelo Judiciário, mormente através de mandado de segurança, numa clara invasão da esfera de competência do Poder Legislativo”.

Dois foram os Ministros que se opuseram ao entendimento proferido pelo relator do caso: Franciulli Netto e Paulo Medina, que se manifestaram favoráveis ao pleito da família, fundamentando-se, justamente, na possível interpretação que se depreende da Constituição Federal, como já destacado anteriormente.

O posicionamento do Judiciário quanto à temática - embora tendente à sua aceitação, consoante julgados recentes acerca do instituto - longe está de consolidar-se definitivamente. Tanto que o caso que será, em breve, julgado pelo Supremo Tribunal Federal quanto à possibilidade de adoção do homeschooling advém de um recurso interposto por família do Rio Grande do Sul, que teve negado, tanto pelo Juiz de Direito quanto pelo Tribunal de Justiça do Estado, o direito a educar sua filha em casa. 
Tamanha a controvérsia acerca do tema, mesmo em se tratando do Poder Judiciário, que, recentemente, em junho deste ano, o Supremo Tribunal Federal avocou a competência de, definitivamente, decidir a temática, assentado o entendimento de ser, ou não, possível a adoção do homeschooling por famílias interessadas neste método de educação.

O Ministro Luís Roberto Barroso, relator do Recurso Extraordinário nº 888.815-RS, a ser decidido pelo Supremo Tribunal Federal brevemente, afirmou que no caso "discutem-se os limites da liberdade dos pais na escolha dos meios pelos quais irão prover a educação dos filhos, segundo suas convicções pedagógicas, morais, filosóficas, políticas e/ou religiosas”.

À luz dos últimos entendimentos proferidos pela Suprema Corte - sempre à luz da mais garantista teoria dos direitos humanos - acredita-se que o homeschooling será, enfim, regulamentado no país, ainda que por uma via não ordinária, eis que estranha ao Poder Legislativo. Resta saber até quando a regulação das mais diversas matérias no país desta forma, em especial, as com repercussão nas diferentes camadas da população, será tida como incomum na ordem jurídica brasileira.

\section{CONCLUSÃO}

Diferentemente do que ocorre em tantos outros países do mundo, no Brasil o homeschooling tem ganhado cada vez mais adeptos não por questões propriamente de cunho íntimo - como o que se verifica nos Estados Unidos da América, em que um dos principais fundamentos para a adoção do método é religioso -, mas, em verdade, pela falência do tradicional sistema educacional no país.

Ora, como bem destacado no artigo, o Brasil tem amargado as últimas posições nos mais diferentes rankings educacionais, o que, dentre tantos outros fatores endógenos e exógenos, demonstra o péssimo nível da educação básica no país.

A caótica situação do sistema educacional do país, inclusive, é de amplo conhecimento das autoridades públicas. Neste sentido, no ano de 2014 foi promulgada a Lei $\mathrm{n}^{\mathrm{o}}$ 13.005, de 25 de Junho de 2014, que aprovou o novo Plano Nacional de Educação - PNE, com vigência de dez anos.

Em referido plano, constam como diretrizes a serem adotadas pelo Poder Público, dentre outras, a erradicação do analfabetismo no país, a melhoria da qualidade da educação e a valorização dos profissionais da área.

Outrossim, as metas ${ }^{24}$ constantes do Plano Nacional de Educação demonstram o quão longe está o país de alcançar níveis satisfatórios na prestação de indigitado serviço público, ainda muito aquém do necessário para o cumprimento dos objetivos previstos na 
Constituição Federal.

É esse, pois, o principal fundamento do crescimento do homeschooling no país: a insatisfação das famílias, sobretudo de maiores rendas, com o sistema educacional tradicional ofertado no Brasil.

Outrossim, conclui-se, no presente artigo, que, ante a inércia do Poder Legislativo na regulamentação do instituto - que já buscada, ao menos, duas vezes, uma arquivada e outra ainda em curso, como destacado - tem sido constante a necessária manifestação do Judiciário sobre o tema, sobretudo após o surgimento da possibilidade de reconhecimento da conclusão do ensino médio com base no índice obtido pelo candidato no ENEM.

A questão chegou, enfim, ao Supremo Tribunal Federal, a quem competirá, no julgamento do Recurso Extraordinário no ${ }^{\circ} 88.815$-RS, de Relatoria do Ministro Luís Roberto Barroso, a regulamentação do homeschooling no Brasil. À luz dos últimos posicionamentos da corte, e, em especial, do Ministro Relator, acredita-se firmemente que o ensino domiciliar restará permitido no país.

\footnotetext{
${ }^{24}$ São metas do Plano Nacional de Educação, dentre outras, a universalização, até 2016, da educação infantil para as criança de 4 (quatro) a 5 (cinco) anos, com ampliação das vagas em creches; a universalização do ensino fundamental para toda a população de 6 (seis) a 14 (catorze) anos, garantindo-se que ao menos 95\% (noventa e cinco por cento) dos alunos concluam a etapa na idade recomendada; alfabetização de todas as crianças até o final do $3^{\circ}$ (terceiro) anos do ensino fundamental; oferecer educação em tempo integral em, no mínimo, 50\% (cinquenta por cento) das escolas públicas; atingir, durante a vigência do plano, determinadas médias do IDEB.
} 


\section{REFERENCIAIS}

ADAM, Natham A. A human rights imperative: extending religious liberty beyond the border. Cornell International Law Journal: Cornell, 2000.

ADRAGÃO, Paulo Pulido. A liberdade religiosa e o Estado. Coimbra: Almedina, 2002.

AFONSO DA SILVA, José. Curso de Direito Constitucional Positivo. 31 ed. São Paulo: Malheiros. 2008.

- Constituição e segurança jurídica. In: ROCHA, Carmen Lucia Antunes (coord.), Constituição e segurança jurídica: direito adquirido, ato jurídico perfeito e coisa julgada: estudos em homenagem à José Paulo Sepúlveda Pertence, $2^{\mathrm{a}}$ ed. Belo Horizonte: Fórum, 2009.

AGUIAR, Alexandre Magno Fernandes Moreira. A situação jurídica do ensino domiciliar no Brasil. Associação Nacional do Ensino Domiciliar. Disponível em: http://www.aned.org.br/portal/downloads/A_situacao_juridica_do_ensino_domiciliar_no_Bra sil.pdf. Acesso em 27 de Dezembro de 2015.

ALEXY, Robert. Conceito e Validade do Direito. 1 ed. São Paulo: Martins Fontes, 2009.

ANDERSON, Brian C. An A for homeschooling. Disponível em: http://www.cityjournal.org/html/10_3_an_a_for_home.html. Acesso em 12 de Janeiro de 2016.

ATIENZA, Manuel. O Direito como argumentação. In: FIGUEROA, Afonso García, et al. (org.). Argumentação e Estado Constitucional. São Paulo: Ícone. 2012.

BARBOSA, Estefânia Maria de Queiroz. Precedentes judiciais e segurança jurídica: fundamentos e possibilidades para a jurisdição constitucional brasileira. São Paulo: Saraiva, 2014.

BARROS, Sérgio Resende de. Contribuição Dialética para o Constitucionalismo. 1 ed. Campinas: Editora Millenium, 2007.

BARROSO, Luís Roberto. Curso de Direito Constitucional Contemporâneo. 3 ed. São Paulo: Saraiva, 2011.

O novo direito constitucional brasileiro. 1 ed. Belo Horizonte: Editora Fórum, 2013.

O Direito Constitucional e a Efetividade de suas Normas. 9 ed. São Paulo: Editora Renovar, 2009.

BOBBIO, Norberto. A Era dos Direitos. Rio de Janeiro: Elsevier, 2004. 
COMPARATO, Fábio Konder. Rumo à justiça. 2 ed. São Paulo: Saraiva, 2013.

DAWKINS, Richard. Deus: um delírio. São Paulo: Companhia das Letras, 2007.

DREISBACH, Daniel L. Thomas Jefferson and the wall of separation between church and state. New York: NYU Press, 2002.

FRANCIULLI NETTO, Domingos. Aspectos constitucionais e infraconstitucionais do ensino fundamental em casa pela família. Associação Nacional do Ensino Domiciliar. Disponível em: http://www.aned.org.br/portal/downloads/Aspectos_Constitucionais.pdf. Acesso em 27 de Dezembro de 2013.

GAARDER, Jostein. O livro das religiões. São Paulo: Companhia das Letras, 2001.

GARCIA, Maria. A constituição e o ensino religioso nas escolas públicas. In: MAZZUOLI, Valério de Oliveira; SORIANO, Aldir Guedes (coord.). Direito à liberdade religiosa: desafios e perspectivas para o século XXI. Belo Horizonte: Editora Fórum, 2009. p. 235-249.

LACANALLO, Luciana Figueiredo et alli. Métodos de ensino e aprendizagem: uma análise histórica e educacional do trabalho didático. Disponível em: http://www.histedbr.fe.unicamp.br/acer_histedbr/jornada/jornada7/_GT4\%20PDF/M\%C9TO DOS\%20DE\%20ENSINO\%20E\%20DE\%20APRENDIZAGEM\%20UMA\%20AN\%C1LISE \%20HIST\%D3RICA.pdf. Acesso em 08 de Janeiro de 2015.

LYMAN, Isabel. Homeschooling: back to future? Disponível em: http://www.cato.org/pubs/pas/pa-294.html. Acesso em 10 de Janeiro de 2016.

MACHADO, Jónatas Eduardo Mendes. A liberdade religiosa numa comunidade constitucional inclusiva. Coimbra: Coimbra Ed., 1996.

MCCONNELL, Michael. Religious freedom at a crossroads. In: STONE, Geoffrey R.; EPSTEIN, Richard A.; SUNSTEIN, Cass R. (Ed.). The bill of rights in the modern state. Chicago: University of Chicago Press, 1992.

SILVA JÚNIOR, Hédio. A liberdade de crença como limite à regulamentação do ensino religioso. 2003. Tese (Doutorado) - Pontifícia Universidade Católica - PUC/SP. São Paulo, 2003.

SORIANO, Aldir Guedes. Liberdade religiosa no direito constitucional e internacional. São Paulo: Juarez de Oliveira, 2002.

VALENTE, David; FRANCO, Alberto. Liberdade religiosa: nova lei anotada e comentada. Lisboa: Dislivro, 2002.

WEIGARTNER NETO, Jayme. Liberdade religiosa na Constituição: fundamentalismo, pluralismo, crenças e cultos. Porto Alegre: Livraria do Advogado, 2007. 